\title{
Prokaryotic Expression of $\alpha$-13 Giardin Gene and Its Intracellular Localization in Giardia lamblia
}

\author{
Xingang Yu, Auwalu Yusuf Abdullahi, Sheng Wu, Weida Pan, Xianli Shi, Wei Hu, \\ Liping Tan, Kangxin Li, Zhen Wang, and Guoqing Li
} Guangdong Provincial Zoonosis Prevention and Control Key Laboratory, College of Veterinary Medicine,
South China Agricultural University, Guangzhou 510542, China

Correspondence should be addressed to Guoqing Li; gqli@scau.edu.cn

Received 7 December 2016; Accepted 18 January 2017; Published 14 February 2017

Academic Editor: Marlene Benchimol

Copyright (C) 2017 Xingang Yu et al. This is an open access article distributed under the Creative Commons Attribution License, which permits unrestricted use, distribution, and reproduction in any medium, provided the original work is properly cited.

\begin{abstract}
To study prokaryotic expression and subcellular localization of $\alpha$-13 giardin in Giardia lamblia trophozoites, $\alpha-13$ giardin gene was amplified and cloned into prokaryotic expression vector pET-28a (+). The positive recombinant plasmid was transformed into $E$. coli BL21(DE3) for expression by using IPTG and autoinduction expression system (ZYM-5052). The target protein was validated by SDS-PAGE and Western blotting and purified by Ni-NTA Resin. Rabbits were immunized with purified fusion proteins for preparation of polyclonal antibody; then the intracellular location of $\alpha-13$ giardin was determined by fluorescence immunoassay. The results showed that the length of $\alpha-13$ giardin gene was $1038 \mathrm{bp}$, encoding a polypeptide of 345 amino acids. The expressed product was a fusion protein with about $40 \mathrm{kDa}$ largely present in soluble form. The target protein accounted for $21.0 \%$ of total proteins after being induced with IPTG, while it accounted for $28.8 \%$ with ZYM-5052. The anti- $\alpha 13$-giardin polyclonal antibody possessed good antigenic specificity as well as excellent binding activity with recombinant $\alpha-13$ giardin. Immunofluorescence assays revealed that $\alpha-13$ giardin was localized in the cytoplasm of G. lamblia trophozoite, suggesting that it is a cytoplasm-associated protein. The present study may lay a foundation for further functional research on $\alpha$-13 giardin of G. lamblia.
\end{abstract}

\section{Introduction}

Giardia lamblia (syn. G. intestinalis, G. duodenalis) is an important zoonotic parasite that infects many mammals, including cats, dogs, and humans. G. lamblia assemblage A and $\mathrm{B}$ infection in individuals can lead to abdominal cramps, acute or chronic diarrhea, and malabsorption [1]. Since the 1970s, the disease has been epidemic or outbreak all over the world; more than 280 million of human symptomatic infections each year only in Africa, Asia, and America are estimated by the World Health Organization (WHO) [2,3].

$G$. lamblia has two stages of life cycle: an infective, immotile cyst and a vegetative, motile trophozoite. The latter (trophozoite) has a pear-shaped body, which is ventrally flattened and bilaterally symmetric. Besides, it has two adhesive disks on the ventral surface, a microtubular median body, two nuclei, and four pairs of flagella: anterior, ventral, lateroposterior, and caudal [4]. Giardins, unique component of the cytoskeleton of Giardia, have been identified as four major classes: alpha $(\alpha)$, beta $(\beta)$, gamma $(\gamma)$, and delta $(\delta)$ [5]. Among them, $21 \alpha$-giardins numbered from $\alpha$-1 to $\alpha$ 19 giardin ( $\alpha-7$ giardin subdivided as $\alpha-7.1, \alpha-7.2$, and $\alpha$ 7.3) have been discovered; their relative molecular masses are about $29 \sim 38 \mathrm{kDa}$, with common characteristic of calcium dependency membrane bound proteins containing acidic phospholipid. They are often associated with the plasma membrane and membrane systems and participate in the movement of the cytoskeleton and signal transduction in the cell, as well as regulating the growth and proliferation of cells and forming the atypical $\mathrm{Ca}^{2+}$ channels $[6,7]$. In addition, some $\alpha$-giardins also participate in the encystation and excystation process of Giardia cysts, preventing their leakage of the cell membrane and disintegration of the cellular structure under the environment of high intestinal bile salts [6].

In recent years, numerous researches on the subcellular localization of $\alpha$-giardins have been reported. Weiland et al. [6] identified 14 coding genes for $\alpha$-giardins ( $\alpha-4$ to $\alpha-6, \alpha$ 8 to $\alpha-13$, and $\alpha-15$ to $\alpha-19)$ in G. lamblia. The localization 
experiments showed that a few $\alpha$-giardins $(\alpha-3, \alpha-5$, and $\alpha$ 17) are localized in the adhesive disc; $\alpha-15$ and $\alpha-16$ giardins had a patchy distribution along the plasma membrane, while the others $(\alpha-1, \alpha-2, \alpha-6, \alpha-7.2, \alpha-7.3, \alpha-9, \alpha-10$, and $\alpha-14)$ were mainly distributed in plasma membrane, adhesive disc, flagella, or cytoplasm. Alpha $1(\alpha-1)$ giardin was identified mainly present in plasma membrane in strains of assemblages A but also in assemblages B and E [8]. Alpha $8(\alpha-8)$ and $\alpha$ 4 giardins were found to be mainly located on the flagella and plasma membrane (the former) and flagella by specific polypeptide, respectively $[9,10]$. The immunofluorescence assay revealed that $\alpha$-11 giardin is mainly localized in the plasma membrane and basal body of the anterior flagella of G. lamblia trophozoite [11]. Recently we have successes on sequence analysis and prokaryotic expression of G. lamblia $\alpha-18$ giardin gene [12]. And we founded that $\alpha 18$ - and $\alpha 12-$ giardin proteins were mainly localized in the flagella and cytoplasm of trophozoites, respectively [13]. However, there are no reports about $\alpha-13$ giardin to date.

In this research work, we proceed to provide new reports on prokaryotic expression of $\alpha-13$ giardin gene and its intracellular localization in G. lamblia assemblage A to lay a foundation for further functional study of $\alpha-13$ giardin.

\section{Materials and Methods}

2.1. Ethics. Animal experiments involved in this study were treated in accordance with the guidelines of the South China Agricultural University Animal Care and Use Committee, which operates under the Animal Welfare Law and Regulations of the Department of Health and Human Services. The South China Agricultural University Animal Care and Use Committee has approved all protocols of this study.

2.2. Cell Culture. Trophozoites of G. lamblia strain WBC6 (ATCC 50803) were cultured in Keister's modified TYI-S-33 medium [14] at $37^{\circ} \mathrm{C}$, which was placed in $10 \mathrm{~mL}$ glass tubes. The cultures were decanted into $15 \mathrm{~mL}$ centrifuge tubes at the end of the logarithmic phase (after about 3 days), and trophozoites were harvested at $5400 \times \mathrm{g}$ for $10 \mathrm{~min}$ at $4^{\circ} \mathrm{C}$.

2.3. PCR Amplification. Total DNA was extracted from trophozoites using a commercial DNA Extraction Kit (Promega, Madison, USA) and quantified by spectrophotometry at $260 \mathrm{~nm}$. Two primers specific to $\alpha-13$ giardin gene, A13E (5'-CGG GAT CCA TGC CTG TTC TGA CCC C$\left.3^{\prime}\right)$ with $\mathrm{Bam}$ HI restriction site (underlined) and A13F (5' CCC AAG CTT CTA ATC CAC ATC CCA GAG CC- $3^{\prime}$ ) with Hind III restriction site (underlined), were designed based on the G. lamblia nucleotide sequence (GL50803_1076). The predicted amplification fragment was $1038 \mathrm{bp}$. A $25 \mu \mathrm{L}$ of PCR reaction mix contained $17.3 \mu \mathrm{L}$ of $\mathrm{ddH}_{2} \mathrm{O}, 2.5 \mu \mathrm{L}$ of $10 \mathrm{x}$ PCR Buffer $\left(\mathrm{Mg}^{2+}\right.$ plus), $2.5 \mu \mathrm{L}$ dNTP, $0.2 \mu \mathrm{L}$ of upstream and downstream primers ( $50 \mathrm{pmol} / \mathrm{L}), 0.3 \mu \mathrm{L}$ of ExTaq DNA polymerase, and $2 \mu \mathrm{L}$ of DNA sample. The thermocycler program consisted of $95^{\circ} \mathrm{C}$ for $5 \mathrm{~min}$, followed by 35 cycles of $94^{\circ} \mathrm{C}$ for $30 \mathrm{~s}, 55.2^{\circ} \mathrm{C}$ for $30 \mathrm{~s}$, and $72^{\circ} \mathrm{C}$ for $2 \mathrm{~min}$, and a final extension at $72^{\circ} \mathrm{C}$ for $7 \mathrm{~min}$. The PCR products were analyzed by electrophoresis in $1 \%$ agarose gels, followed by ethidium bromide staining and photographed under UV light.

2.4. Construction of Recombinant Plasmids. The obtained PCR products were purified by using DNA gel Extraction Kit (Omega, Guangzhou, China) and cloned into pMD18T (TaKaRa, Dalian, China) according to the manufacturer's instructions. Then the PMD18-T-g- $\alpha 13$ plasmid was transformed into JM109 competent cells. The positive colonies carrying the target gene were selected by fresh LB agar plates supplemented with $100 \mathrm{mg} / \mathrm{mL}$ of ampicillin after growing for $12 \mathrm{~h}$ at $37^{\circ} \mathrm{C}$; then the PMD18-T-g- $\alpha 13$ was purified using the Plasmid Mini Kit (Omega, Guangzhou, China). The obtained plasmid and pET-28a (+) were digested with Bam $\mathrm{HI} /$ Hind III (TaKaRa, Dalian, China) and connected by T4 DNA ligase (TaKaRa, Dalian, China) to create recombinant plasmids which were confirmed by PCR and Bam HI/Hind III digestion and then sequenced by Sangon Biotech Company (Shanghai, China). The correct recombinant prokaryotic expression plasmids were named as pET-28a(+)-g- $\alpha 13$.

2.5. Expression of $\alpha-13$ Giardin. The recombinant plasmids were transformed into E. coli BL21(DE3) (TransGen Biotech, Beijing, China). Freshly transformed bacteria were inoculated into $\mathrm{LB}$ medium $(50 \mu \mathrm{g} / \mathrm{mL}$ kanamycin) and grew at $37^{\circ} \mathrm{C}$ with continuous shaking cultivation at $200 \mathrm{rpm}$ until the absorbance at $600 \mathrm{~nm}$ reached $0.4 \sim 0.6$. The $\alpha-13$ giardin fusion protein was expressed under the induction of isopropyl-1-thio- $\beta$-D-galactopyranoside (IPTG); firstly, the expression conditions were optimized by adjusting IPTG concentrations $(0.2,0.4,0.6,0.8,1.0$, and $1.2 \mathrm{mM})$, induction time $(1,3,5$, and $7 \mathrm{~h})$, and culturing temperature $(16,20,25$, 30 , and $37^{\circ} \mathrm{C}$ ). Then, they were expressed by autoinduction expression system (ZYM-5052); the bacterium solutions cultivated by ZYM-5052 for 3 16 h were collected, respectively. For details, refer to Studier [15] with few modifications. The cultures were harvested at $9600 \times \mathrm{g}$ for $10 \mathrm{~min}$ at $4^{\circ} \mathrm{C}$ after washing the cell pellet in phosphate buffer (containing $0.1 \%$ Tween-20).

2.6. SDS-PAGE and Western Blotting Analysis. Samples containing $40 \mu \mathrm{L}$ of total proteins were boiled for $10 \mathrm{~min}$ after adding $10 \mu \mathrm{L} 5 \mathrm{x}$ SDS loading sample buffer, then stored for $5 \mathrm{~min}$ at $-20^{\circ} \mathrm{C}$, and centrifuged at $16200 \times \mathrm{g}$ for $5 \mathrm{~min}$. Then, $10 \mu \mathrm{L}$ supernatant of each sample was analyzed by SDS-PAGE performed in Tris-glycine system, using 12\% gels. Proteins were visualized by staining with Coomassie brilliant blue G250. The target protein expression was detected by LiCor Odyssey infrared Imaging system (LiCor, Nebraska, USA) and analyzed by Quantity One 1-D Analysis Software (BioRad, Hercules, USA). Ten microliters of each preprocessed protein sample was separated on a $12 \%$ SDS-PAGE at $120 \mathrm{~V}$ and transferred to nitrocellulose membrane (Roche, Indianapolis, USA) for $45 \mathrm{~min}$ at $120 \mathrm{~mA}$. The membrane was blocked overnight at $4^{\circ} \mathrm{C}$ in $0.1 \%$ Tween-20-PBS containing $5 \%$ nonfat milk. The $\alpha-13$ giardin proteins were detected using the ECL Plus Western blotting detection system (Tiannon, Shanghai, China) by rabbit anti-His tag monoclonal antibody (diluted 1:2000) and horseradish peroxidase- (HRP-) labeled 
goat anti-rabbit IgG antibody (Transgen, Beijing, China) at dilution of $1: 3000$.

2.7. Protein Purification. For purification of soluble $\alpha-13$ giardins, BL21 (DE3) cells harboring pET-28a(+)-g- $\alpha 13$ were cultured in $1000 \mathrm{~mL}$ of $\mathrm{LB}$ medium for $5 \mathrm{~h}$ at $25^{\circ} \mathrm{C}$ with $50 \mu \mathrm{g} / \mathrm{mL}$ kanamycin. The cultivated cells were harvested by centrifugation at $8,000 \times \mathrm{g}$ for $10 \mathrm{~min}$, resuspended in PBS, and subjected to sonication (SCIENTZ, Ningbo, China). Soluble and insoluble fractions were separated by centrifugation at $10000 \times \mathrm{g}$ for $30 \mathrm{~min}$ at $4^{\circ} \mathrm{C}$. The supernatant was applied on a $\mathrm{Ni}^{2+}$ nitrilotriacetic acid column in binding buffer (0.3 M NaCl, $50 \mathrm{mM} \mathrm{NaH} \mathrm{PO}_{4}, 10 \mathrm{mM}$ Tris-base, and $\mathrm{pH}$ $8.0)$, eluted with different concentrations of imidazole $(0.01$, $0.02,0.05,0.1,0.15$, and $0.2 \mathrm{M}$ ), and analyzed by SDS-PAGE. The total protein concentrations in the supernatant were determined by using a Bicinchoninic Acid (BCA) Protein Assay Kit (ComWin Biotech, Beijing, China) according to the manufacturer's instructions.

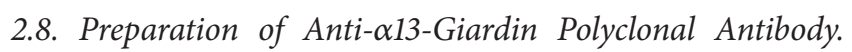
The anti- $\alpha 13$-giardin polyclonal antibody was prepared as described [16] with some modifications. Briefly, two male New Zealand white rabbits $(2.5 \mathrm{~kg})$ were inoculated with $1 \mathrm{~mL}(1 \mathrm{mg} / \mathrm{mL})$ purified anti- $\alpha 13$-giardin protein emulsified with an equal amount of Freund's complete adjuvant via subcutaneous injection. Immunization of each rabbit was boosted four times by inoculation of $1 \mathrm{~mL}$ antigen mixed with an equal volume of Freund's incomplete adjuvant at 1-week intervals. Blood sample was collected 7 days after final injection; the sera were obtained to determine the antibody titer by indirect enzyme linked immunosorbent assay (ELISA). Prior to first immunization, a certain amount of serum was taken from ear marginal veins of each rabbit as negative control.

2.9. Determination of Antibody Titers by ELISA. The antibody titers were determined using indirect ELISA as described [17]. Briefly, purified $\alpha 13$-giardin proteins were coated on plates at $200 \mu \mathrm{L}$ per well in 96 -well plates at $4^{\circ} \mathrm{C}$ overnight. The plates were washed three times with PBS containing $0.1 \%$ Tween20 (PBST). The coated wells were blocked for $1 \mathrm{~h}$ at $37^{\circ} \mathrm{C}$ with $200 \mu \mathrm{L}$ of $5 \%$ nonfat milk in PBST, then washed three times with PBST, and incubated with $100 \mu \mathrm{L}$ of anti- $\alpha 13$-giardin serum by serial dilutions (from $1: 100$ to $1: 243,000$, normal serum as negative control). After incubation for $1 \mathrm{~h}$ at $37^{\circ} \mathrm{C}$, the wells were washed and incubated with $200 \mu \mathrm{L}$ of HRPconjugated goat anti-rabbit IgG antibody (dilution, 1:4,000; Transgen, Beijing, China). The reaction was terminated with the stop buffer, and the absorbance at $450 \mathrm{~nm}$ was measured using a microplate reader (Allsheng, Hangzhou, China).

2.10. Determination of Antisera Specificity. G. lamblia trophozoite lysates were extracted using Total Protein Extraction Kit (Vazyme, Nanjing, China) according to manufacturer's instructions. Total trophozoite extract and the purified $\alpha$ 13 giardin fusion protein were subjected to $12 \%$ SDS-PAGE and transferred to nitrocellulose membrane. The membrane was blocked at $37^{\circ} \mathrm{C}$ for $1 \mathrm{~h}$ with $5 \%$ nonfat dry milk in PBST, followed by incubation with the anti- $\alpha 13$ giardin antibody $\left(1: 200\right.$ dilution) at $4^{\circ} \mathrm{C}$ overnight. After three washes with PBST (containing 0.1\% Tween-20), the membrane was incubated for $1 \mathrm{~h}$ at $37^{\circ} \mathrm{C}$ with HRP-conjugated goat antirabbit IgG (1:2000 dilution). Then the membrane was rinsed three times, and the protein bands were visualized with an enhanced chemiluminescence protocol and the Western blotting detection system (Tiannon, Shanghai, China).

\subsection{Immunofluorescence (IF) Staining of G. lamblia Tropho-} zoites. The immunofluorescence staining of G. lamblia trophozoites was carried out as described in previous reports [11, 18] with some modifications. Briefly, G. lamblia trophozoites were allowed to attach to sterile glass coverslips, fixed for $15 \mathrm{~min}$ with methanol, and permeabilized for $10 \mathrm{~min}$ at $-20^{\circ} \mathrm{C}$ with $0.5 \%-1 \%$ Trion X-100/PBS. The cells were rinsed three times with PBS for 5 min each time. And they were incubated for 60 min with blocking buffer (5\% goat serum) (ComWin Biotech, Beijing, China). Primary antibody was diluted in dilution buffer (at 1:500), after reacting with the rabbit anti$\alpha 13$-giardin antiserum for $1 \mathrm{~h}$; the samples were washed three times with PBS and then incubated for $1 \mathrm{~h}$ in the dark with Alexa Fluor 488 anti-rabbit IgG $(\mathrm{H}+\mathrm{L})$ from goat $(1: 200)$ (Beyotime, Jiangsu, China) at room temperature. Coverslips were kept in a humidified chamber to avoid evaporation. They were rinsed three times with PBS before counterstaining with DAPI ( $4^{\prime}, 6^{\prime}$-diamidino-2-phenylindole; Genecopoeia, Rockville, USA). After five washes with PBS, fluorescence staining was visualized by using Nikon DS-Qi2 Imaging fluorescence microscope (Nikon, Tokyo, Japan), with 100x oil immersion objectives (Size: $1608 \times 1608$ ), and images were processed using NIS Elements (version 4.50) Imaging software.

\section{Results}

3.1. Construction of Recombinant Plasmid. PCR amplification from $\alpha$-13 giardin gene showed that the specific fragment was about $1000 \mathrm{bp}$, which was consistent to the expected size (Figure 1(a)). The identification of recombinant plasmid pET$28 \mathrm{a}(+)-\mathrm{g}-\alpha 13$ digested with Bam HI and Hind III was proved to be successful (Figure 1(b)).

3.2. The Expression of $\alpha-13$ Giardin after Induction. The results showed that the target protein reached the maximum and accounted for $21.0 \%$ of the total cell proteins after induction with $0.6 \mathrm{mmol} / \mathrm{L}$ IPTG for $5 \mathrm{~h}$ at $25^{\circ} \mathrm{C}$. Comparing the induction effect by ZYM-5052 with conventional IPTG induction at the same temperature, the results showed that the target protein reached the maximum and accounted for $28.8 \%$ of the total cell proteins after being induced by ZYM5052 for $14 \mathrm{~h}$ at $37^{\circ} \mathrm{C}$, while it accounted for $6.7 \%$ of the total cell proteins after being induced with $0.6 \mathrm{mmol} / \mathrm{L}$ IPTG for $5 \mathrm{~h}$ at $37^{\circ} \mathrm{C}$ (Figure 2(a)).

3.3. Identification and Purification of $\alpha-13$ Giardin. SDSPAGE results showed that both the supernatant and precipitate contained the target protein, but the supernatant had 


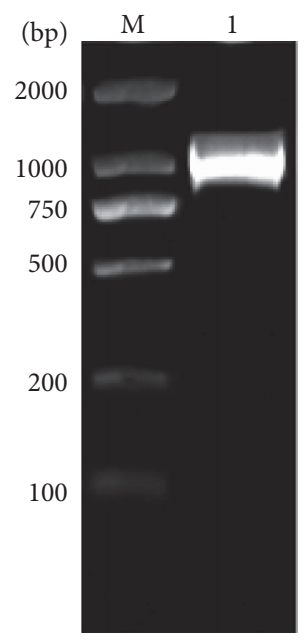

(a)

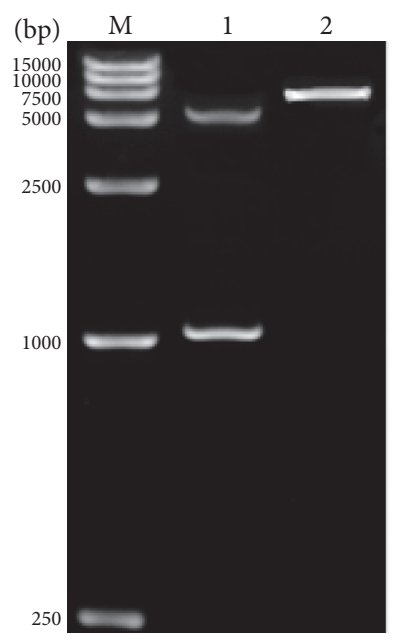

(b)

FIGURE 1: Amplification of $\alpha$-13 giardin gene (a) and identification of recombinant plasmid pET-28a(+)-g- $\alpha 13$ (b). (a) M, DNA marker DL2,000 and 1, PCR amplicons. (b) M, DNA marker DL-15,000; 1, digested pET-28a(+)-g- $\alpha 13$; and 2, undigested pET-28a(+)-g- $\alpha 13$.

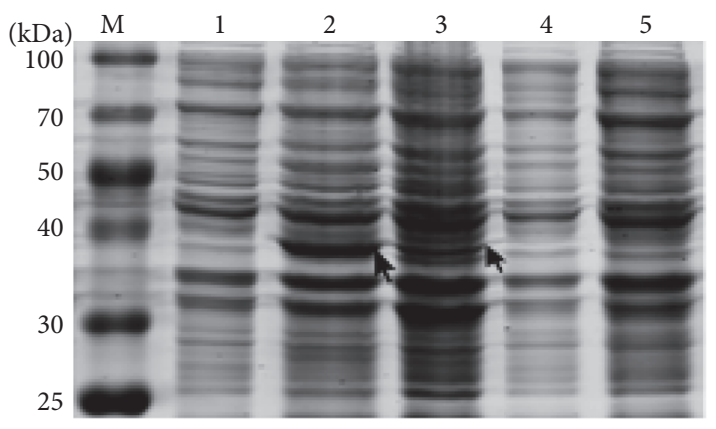

(a)

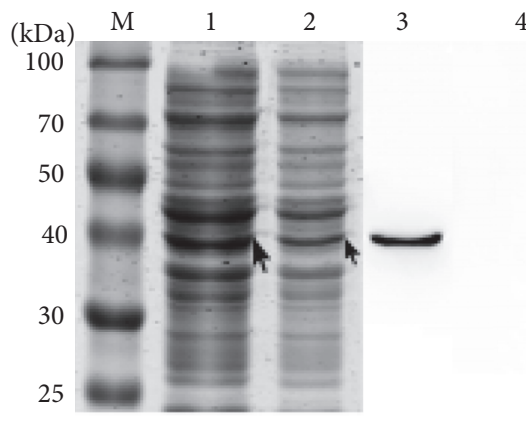

(b)

Figure 2: SDS-PAGE ( $\mathrm{a}, \mathrm{b})$ and Western blot (b) analysis of $\alpha-13$ giardin fusion protein. (a) M, standard protein marker; 1, pET$28 \mathrm{a}(+) /$ BL21(DE3); 2 , total cell lysate of pET-28a(+)-g- $\alpha 13$ induced with ZYM-5052 medium; 3, total cell lysate of pET-28a(+)-g- $\alpha 13$ induced with $0.5 \mathrm{mM}$ IPTG; 4, total cell lysate of uninduced pET-28a(+)-g- $\alpha 13$; and 5, BL21(DE3). (b) M, standard protein marker; 1 , ultrasound supernatant of pET-28a(+)-g- $\alpha 13 /$ BL21(DE3); and 2, ultrasound precipitation of pET-28a(+)-g- $\alpha 13 /$ BL21(DE3). (b) 3, total cell lysate of pET$28 \mathrm{a}(+)$-g- $\alpha 13 / \mathrm{BL} 21(\mathrm{DE} 3)$ induced with $0.5 \mathrm{mM}$ IPTG and 4, total cell lysate of pET-28a(+)-g- $\alpha 13 / \mathrm{BL} 21(\mathrm{DE} 3)$.

a higher amount of the target protein than the precipitate, indicating that the recombinant proteins mainly existed in soluble form (Figure 2(b)). The Western blotting analysis showed that the rabbit anti-His tag monoclonal antibody and HRP-labeled goat anti-rabbit IgG antibody reacted with a protein of about $40 \mathrm{kDa}$ (Figure 2(b)), which is consistent with the theoretical value of the $\alpha-13$ giardin. SDS-PAGE analysis indicated that the $\alpha-13$ giardin fusion protein could be eluted with $0.1,0.15$, and $0.2 \mathrm{mM}$ imidazole (Figure 3 ). However, the eluate with $0.1 \mathrm{mM}$ imidazole contained several impurity proteins, while the one with $0.2 \mathrm{mM}$ imidazole had loss of the target protein, so the eluate with $0.15 \mathrm{mM}$ imidazole was more satisfactory. The protein detecting results revealed that the total protein concentration was $1.17 \mathrm{mg} / \mathrm{mL}$.

3.4. Specificity of Anti- $\alpha 13$ Giardin Polyclonal Antibody. The anti- $\alpha 13$ giardin polyclonal antibody titer detected by ELISA was more than $1: 243,000$. The candidate antisera reacted with recombinant $\alpha-13$ giardin expressed in $E$. coli as a polyhistidine fusion protein (Figure 4(a)) and were specific to a $40 \mathrm{kDa}$ protein band with total trophozoite lysates in Western blot assay (Figure 4(b)). Results showed that the polyclonal antibody was specific to the $\alpha-13$ giardin of trophozoites.

3.5. Intracellular Location of $\alpha-13$ Giardin in Trophozoites. Immunofluorescence assay showed that the fluorescence signals of Alexa Fluor 488 anti-rabbit IgG $(\mathrm{H}+\mathrm{L})$ from goat were significantly distributed in the cytoplasm of trophozoite but not in the flagella and plasma membranes (Figures 5(a) and 5(b)). The preimmune serum (control) did not react with the trophozoite, and no fluorescence signal appeared (Figure 5(c)). It revealed that $\alpha-13$ giardin was localized in the cytoplasm in trophozoites of G. lamblia assemblage A. 


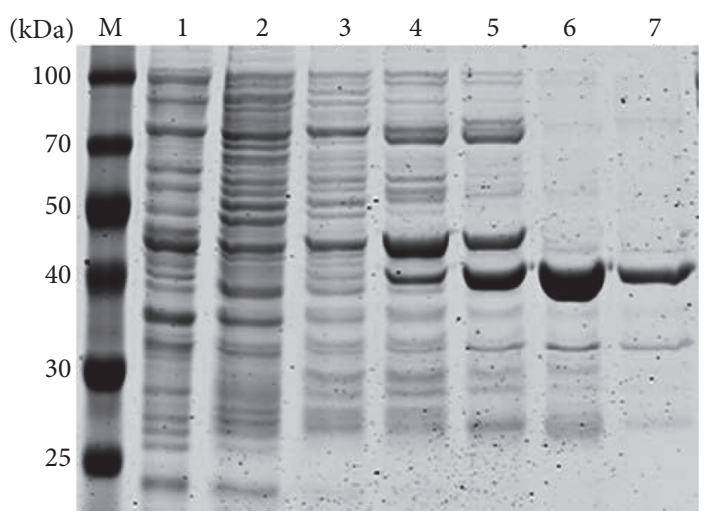

FIGURE 3: SDS-PAGE analysis of $\alpha$-13 giardin fusion protein after purification by Ni-NTA Resin column. M: standard protein marker; 1: cell lysate (supernatant); and 2-7: proteins eluted with imidazole of 10, 20, 50, 100, 150, and $200 \mathrm{mmol} / \mathrm{L}$.

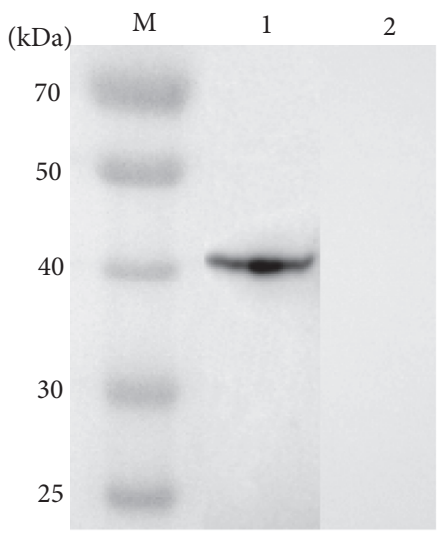

(a)

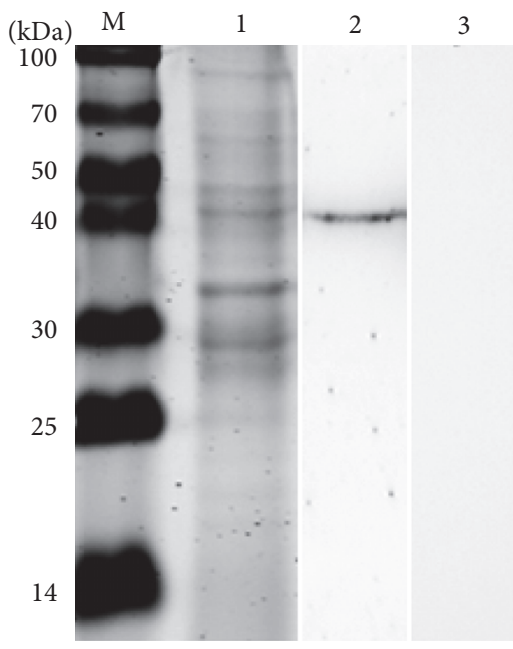

(b)

FIGURE 4: Confirmation of specificity of anti- $\alpha 13$ giardin antibodies. (a) Western blotting of recombinant $\alpha$-13 giardin proteins. 1, reactivity of the anti- $\alpha 13$-giardin antibodies with the recombinant proteins and 2, control with preimmune serum. (b) Western blotting of G. lamblia trophozoite lysates separated by SDS-PAGE (12\% acrylamide). M, standard protein marker; 1 , Coomassie stain of total trophozoite lysates; 2 , specific reactivity of the anti- $\alpha 13$ giardin antibodies with trophozoite lysates; and 3, control with preimmune serum.

\section{Discussion}

Four classes of giardins, $\alpha, \beta, \gamma$, and $\delta$, have been identified as cytoskeleton components of the Giardia. The genome of $G$. lamblia possesses a total of $21 \alpha$-giardin encoding genes, which are $\alpha$-giardins numbered from $\alpha-1$ to $\alpha$-19 giardin ( $\alpha-7$ giardin subdivided as $\alpha-7.1, \alpha-7.2$, and $\alpha-7.3)$. The different $\alpha$ giardins have great differences in the protein expression level, the subcellular localization, and biological functions. The overexpression of some $\alpha$-giardins often affects the division, proliferation, and differentiation of the cells, even leading to death of the parasite, which suggests that the $\alpha$-giardins possess important biological functions.

This work presents the first report on prokaryotic expression of the $\alpha-13$ giardin gene of $G$. lamblia. There are many factors that affect the expression of foreign genes, such as, the target encoding gene, the expression vector, the competent cell, the cultivation condition of the E. coli, and the induction methods [19]. Previous studies [6, 19, 20] have indicated that the genome of the eukaryotic protist Giardia is compact in structure, contains few introns, and has simplified machinery for DNA replication and transcription. And $\alpha$ giardin genes have been known to lack introns, so $\alpha-13$ giardin gene was cloned directly using genomic DNAs in the present study. The results showed that the amplification of $\alpha-13$ giardin gene, construction of pET-28a $(+)-g-\alpha 13$, and the expression of $\alpha-13$ giardin in BL21(DE3) were successful. However, in the initial stage of experiment, the production of target protein was very low and mainly existed in a form of inclusion body at $37^{\circ} \mathrm{C}$ as the optimal temperature for bacterial growth. Moreover, some expressing host cells had lost their expression plasmid. To overcome these limitations, we tried two solutions. Firstly, we compared the expression and solubility of fusion protein at $37^{\circ} \mathrm{C}, 30^{\circ} \mathrm{C}, 25^{\circ} \mathrm{C}, 20^{\circ} \mathrm{C}$, and $16^{\circ} \mathrm{C}$ with different IPTG concentrations $(0.2,0.4,0.6,0.8,1.0$, and $1.2 \mathrm{mM}$ ) and different induction time $(1,3,5,7,9$, and 

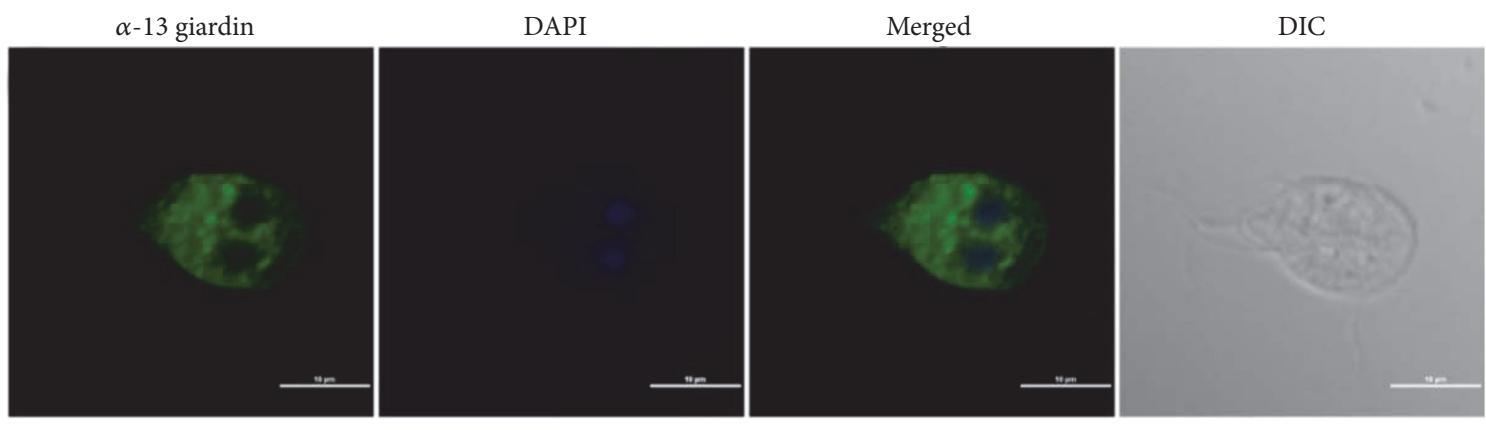

(a)
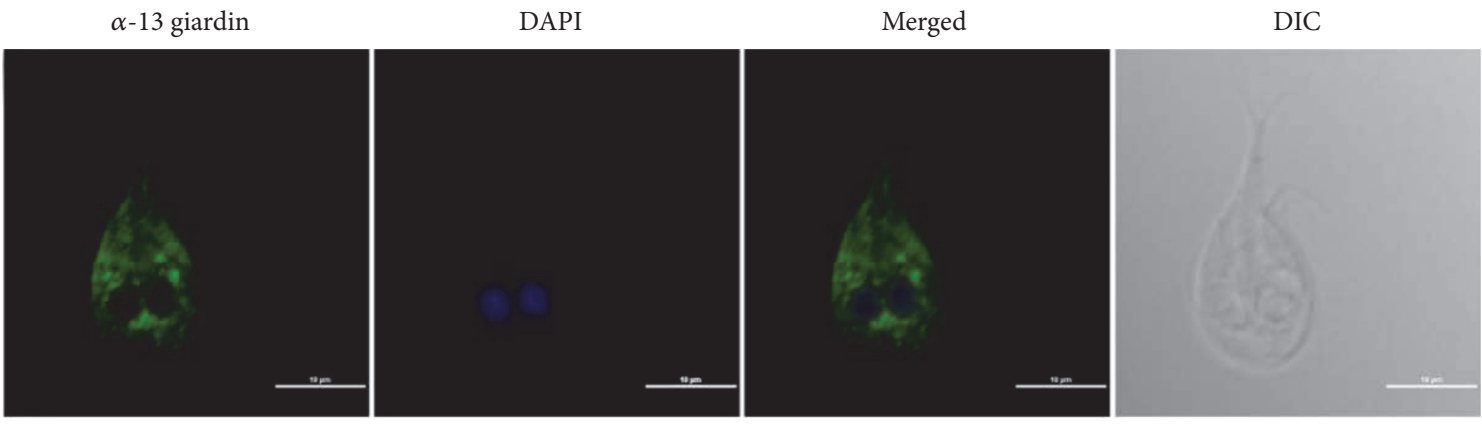

(b)
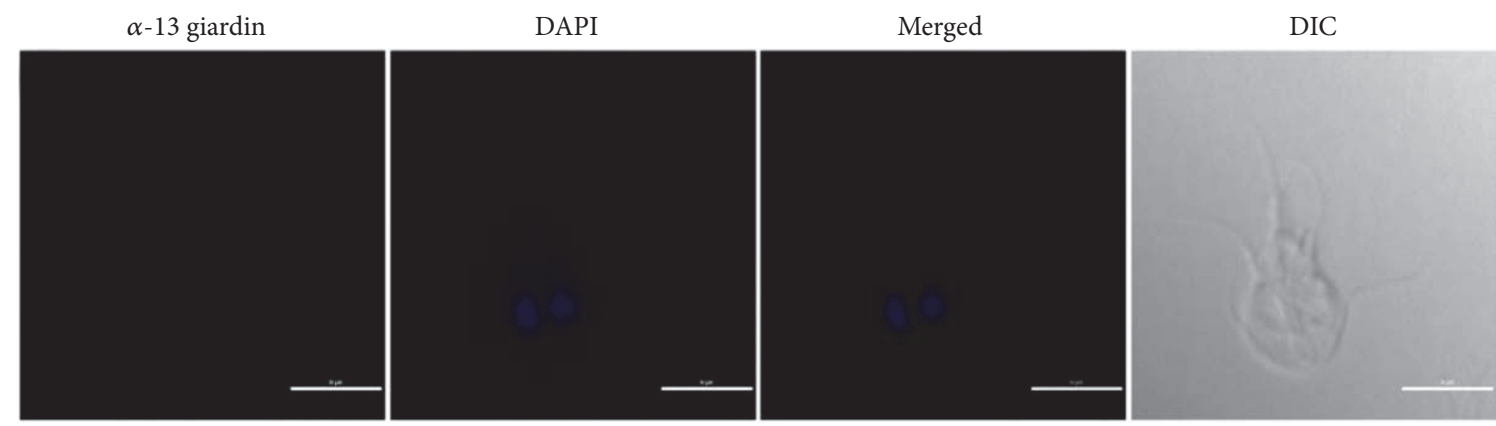

(c)

FIGURE 5: Immunofluorescent localization of $\alpha-13$ giardin in G. lamblia trophozoites. (a, b): Fluorescence microscopy images of single trophozoite (green) incubated with anti- $\alpha 13$-giardin antiserum. (c): Control with preimmune serum. DIC, bright-field differential interference contrast. Nuclear DNA is stained blue with DAPI. The scale bar is $10 \mu \mathrm{m}$.

$11 \mathrm{~h}$ ); the optimized induction condition was for $5 \mathrm{~h}$ at $25^{\circ} \mathrm{C}$ with $0.5 \mathrm{mM}$ IPTG to the recombinant BL21 at $\mathrm{OD}_{600} 0.8$. Secondly, they were expressed by autoinduction expression system (ZYM-5052); the results show that the quantity and stability of the functional recombinant plasmid in the autoinduction expression system had been improved. This work demonstrates the importance of selection of heterologous host and induction methods for successful production of soluble recombinant protein.

Different giardins have different subcellular localizations in G. lamblia trophozoites and may play different biological functions. Many $\alpha$-giardins $(\alpha-2, \alpha-4, \alpha-5, \alpha-8, \alpha-9, \alpha-10$, $\alpha-11, \alpha-14, \alpha-17$, and $\alpha-19)$ have been shown to localize in flagella; a few $\alpha$-giardins such as $\alpha-3, \alpha-5$, and $\alpha$-17 were found localized in the disc; some $\alpha$-giardins such as $\alpha-1, \alpha-2, \alpha-7.2$, $\alpha-7.3, \alpha-8$, and $\alpha$-11 were located in the plasma membrane, and other $\alpha$-giardins $(\alpha-6, \alpha-7.3, \alpha-12, \alpha-15$, and $\alpha-16)$ had spotty cytoplasmic distribution [6,9-11, 13, 18]. Previous studies $[6,7]$ indicated that $\alpha$-giardins are mainly involved in the cytoskeleton, flagella motility, membrane stability, and attachment of Giardia. Recent studies [21-23] revealed that $\alpha-1$ giardin contains an epitope between amino acids 160 and 200 that is highly immunogenic and can stimulate the production of anti-Giardia antibodies (IgA and IgG2a), which is a suitable candidate antigen for a vaccine against giardiasis. In addition, compared with Giardia albendazole(Abz-) sensitive clones, Abz-resistant clones had upregulated the $\alpha$-2 giardin, which suggests that $\alpha-2$ giardin may function as annexin to cope with reactive oxygen species in Abzresistant clones [24]. These discoveries of the functions of $\alpha$ giardins will aid in further research on the prevention and control of giardiasis. However, there are no reports about the localization and relevant biological functions of $\alpha-13$ giardin to date. The present study on $\alpha-13$ giardin localization 
extended the list of giardins located in the cytoplasm. Though the precise function of $\alpha-13$ giardin remains unknown, its specific localization in the cytoplasm suggests that the protein may be associated with a particular cytoplasmic structure like free ribosomes or profiles of the endoplasmic reticulum and it may make contact with the cytoskeleton within the parasite. The exact subcellular location and specific biological function of $\alpha-13$ giardin need further research in the future.

In conclusion, this work presents the first report on prokaryotic expression of the $\alpha-13$ giardin gene and its subcellular location of G. lamblia assemblage A (strain WBC6). It may lay the foundation for further functional research on $\alpha-13$ giardin of zoonotic G. lamblia assemblage A.

\section{Competing Interests}

The authors declare that they have no competing interests.

\section{Acknowledgments}

This work was funded by the National Natural Science Foundation of China (Grant nos. 31272551 and 31672541). G. lamblia trophozoite assemblages A were offered by Professor Zhaorong Lun from Southern China Research Center of Parasitic Biology, Sun Yat-Sen University, China. The authors would like to thank him and Dr. Yiting Xie for valuable contributions to this study.

\section{References}

[1] P. G. Carranza and H. D. Lujan, "New insights regarding the biology of Giardia lamblia," Microbes and Infection, vol. 12, no. 1, pp. 71-80, 2010.

[2] A. A. Escobedo and S. Cimerman, "Giardiasis: a pharmacotherapy review," Expert Opinion on Pharmacotherapy, vol. 8, no. 12, pp. 1885-1902, 2007.

[3] M. N. Martínez-Gordillo, A. González-Maciel, R. ReynosoRobles, E. Montijo-Barrios, and M. Ponce-Macotela, "Intraepithelial Giardia intestinalis: a case report and literature review," Medicine, vol. 93, no. 29, article no. e277, 2014.

[4] K. P. Carvalho and L. H. Monteiro-Leal, "The caudal complex of Giardia lamblia and its relation to motility," Experimental Parasitology, vol. 108, no. 3-4, pp. 154-162, 2004.

[5] C. J. Wei, X. F. Tian, and S. Q. Lu, "Research progress on specific cytoskeletal proteins-giardins in Giardia lamblia," International Journal of Medical Parasitic Diseases, vol. 41, no. 3, pp. 163-169, 2014.

[6] M. E.-L. Weiland, A. G. McArthur, H. G. Morrison, M. L. Sogin, and S. G. Svärd, "Annexin-like alpha giardins: a new cytoskeletal gene family in Giardia lamblia," International Journal for Parasitology, vol. 35, no. 6, pp. 617-626, 2005.

[7] M. E.-L. Weiland, J. E. D. Palm, W. J. Griffiths, J. M. McCaffery, and S. G. Svärd, "Characterisation of alpha-1 giardin: an immunodominant Giardia lamblia annexin with glycosaminoglycanbinding activity," International Journal for Parasitology, vol. 33, no. 12, pp. 1341-1351, 2003.

[8] C. Feliziani, M. C. Merino, M. R. Rivero, U. Hellman, M. C. Pistoresi-Palencia, and A. S. Rápolo, "Immunodominant proteins $\alpha$ - 1 giardin and $\beta$-giardin are expressed in both assemblages A and B of Giardia lamblia," BMC Microbiology, vol. 11, article 233, 2011.
[9] C. J. Wei, X. F. Tian, R. D. Adam, and S. Q. Lu, "Giardia lamblia: intracellular localization of alpha8-giardin," Experimental Parasitology, vol. 126, no. 4, pp. 489-496, 2010.

[10] Y. Wang, W. S. Yang, J. Li et al., "Preparation of a polyclonal antibody specific for $\alpha-4$ giardin and its immunoelectron microscopic localization," Journal of Pathogen Biology, vol. 7, no. 12, pp. 916-919, 2012.

[11] J. Kim, H. Y. Lee, M.-A. Lee, T.-S. Yong, K.-H. Lee, and S.-J. Park, "Identification of $\alpha$-11 giardin as a flagellar and surface component of Giardia lamblia," Experimental Parasitology, vol. 135, no. 2, pp. 227-233, 2013.

[12] S. Wu, X. Yu, A. Y. Abdullahi et al., "Sequence analysis and prokaryotic expression of Giardia lamblia $\alpha$-18 giardin gene," Infection, Genetics and Evolution, vol. 38, pp. 13-18, 2016.

[13] S. Wu, W. Pan, X. Shi et al., "Immunolocalization of $\alpha 18$ and $\alpha 12$-giardin in Giardia lamblia trophozoites," Parasitology Research, vol. 115, no. 11, pp. 4183-4187, 2016.

[14] D. B. Keister, "Axenic culture of Giardia lamblia in TYI-S-33 medium supplemented with bile," Transactions of the Royal Society of Tropical Medicine and Hygiene, vol. 77, no. 4, pp. 487488, 1983.

[15] F. W. Studier, "Protein production by auto-induction in highdensity shaking cultures," Protein Expression and Purification, vol. 41, no. 1, pp. 207-234, 2005.

[16] X. Ren, M. Wang, J. Yin, Y. Ren, and G. Li, "Heterologous expression of fused genes encoding the glycoprotein 5 from PRRSV: a way for producing functional protein in prokaryotic microorganism," Journal of Biotechnology, vol. 147, no. 2, pp. 130-135, 2010.

[17] H. L. Zheng, H. Li, Y. S. Sun, Z. Y. Yang, and Q. Yu, "Parathyroid hormone-related peptide (PTHrP): prokaryotic expression, purification, and preparation of a polyclonal antibody," Genetics and Molecular Research, vol. 13, no. 3, pp. 6448-6454, 2014.

[18] M. Šarić, A. Vahrmann, D. Niebur, V. Kluempers, A. B. Hehl, and H. Scholze, "Dual acylation accounts for the localization of $\alpha 19$-giardin in the ventral flagellum pair of Giardia lamblia," Eukaryotic Cell, vol. 8, no. 10, pp. 1567-1574, 2009.

[19] R. D. Adam, "Biology of Giardia lamblia," Clinical Microbiology Reviews, vol. 14, no. 3, pp. 447-475, 2001.

[20] H. G. Morrison, A. G. McArthur, F. D. Gillin et al., "Genomic minimalism in the early diverging intestinal parasite Giardia lamblia," Science, vol. 317, no. 5846, pp. 1921-1926, 2007.

[21] G. Jenikova, P. Hruz, M. K. Andersson et al., “ $\alpha 1$-giardin based live heterologous vaccine protects against Giardia lamblia infection in a murine model," Vaccine, vol. 29, no. 51, pp. 9529-9537, 2011.

[22] G. Lopez-Romero, J. Quintero, H. Astiazarán-García, and C. Velazquez, "Host defences against Giardia lamblia," Parasite Immunology, vol. 37, no. 8, pp. 394-406, 2015.

[23] S. J. Emery, D. Pascovi, E. Lacey, and P. A. Haynes, “The generation gap: proteome changes and strain variation during encystation in Giardia duodenalis," Molecular and Biochemical Parasitology, vol. 201, no. 1, pp. 47-56, 2015.

[24] M. T. Paz-Maldonado, R. Argüello-García, M. Cruz-Soto, G. Mendoza-Hernández, and G. Ortega-Pierres, "Proteomic and transcriptional analyses of genes differentially expressed in Giardia duodenalis clones resistant to albendazole," Infection, Genetics and Evolution, vol. 15, pp. 10-17, 2013. 

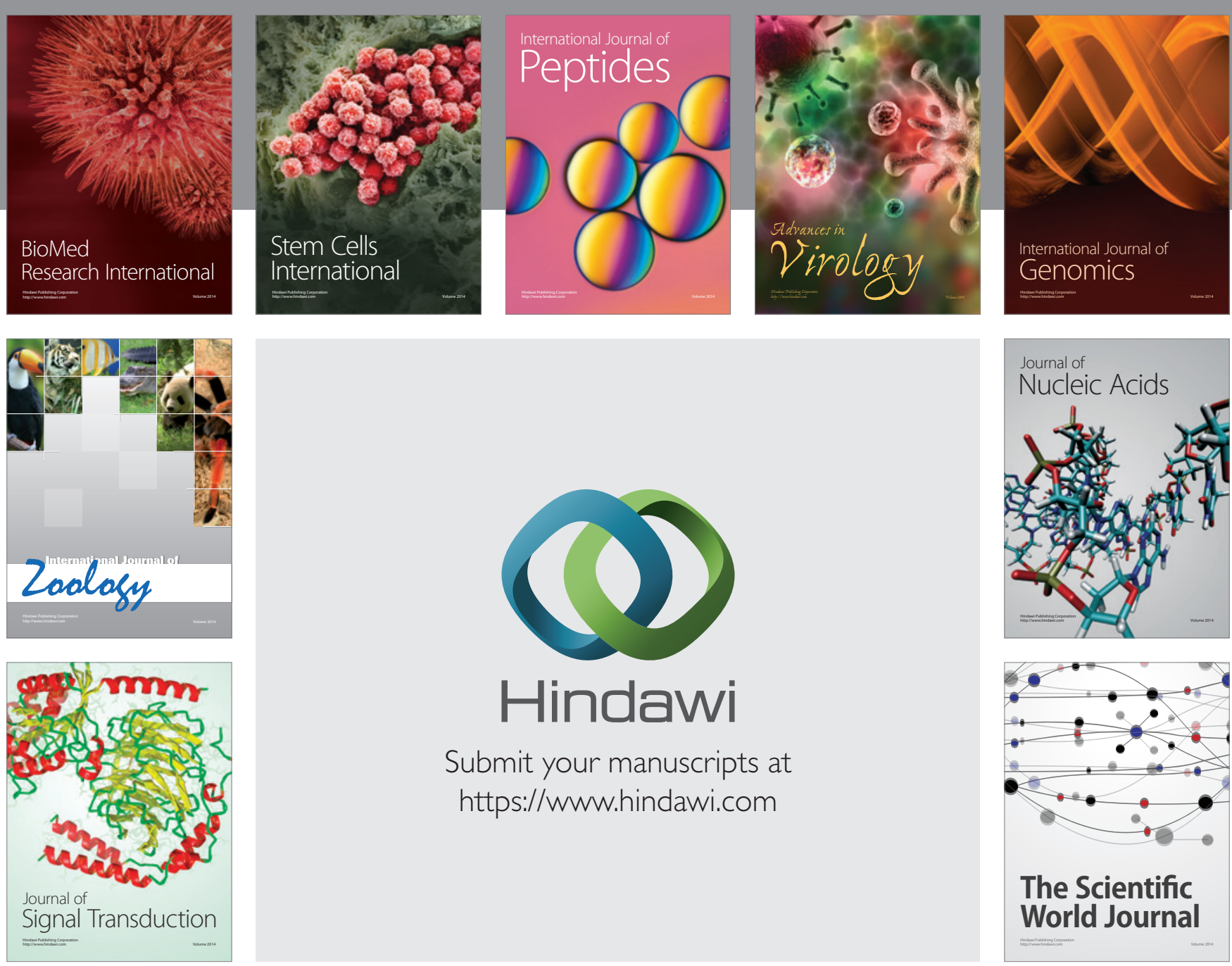

Submit your manuscripts at

https://www.hindawi.com
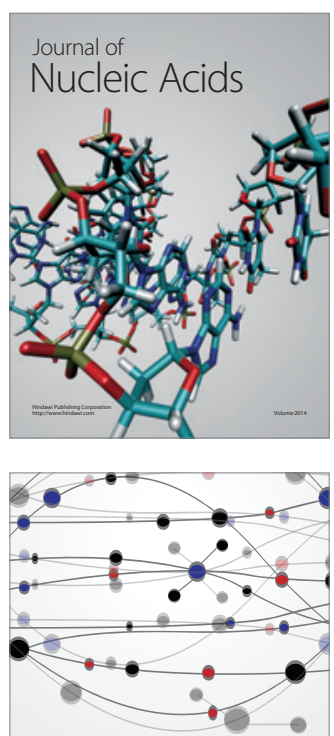

The Scientific World Journal
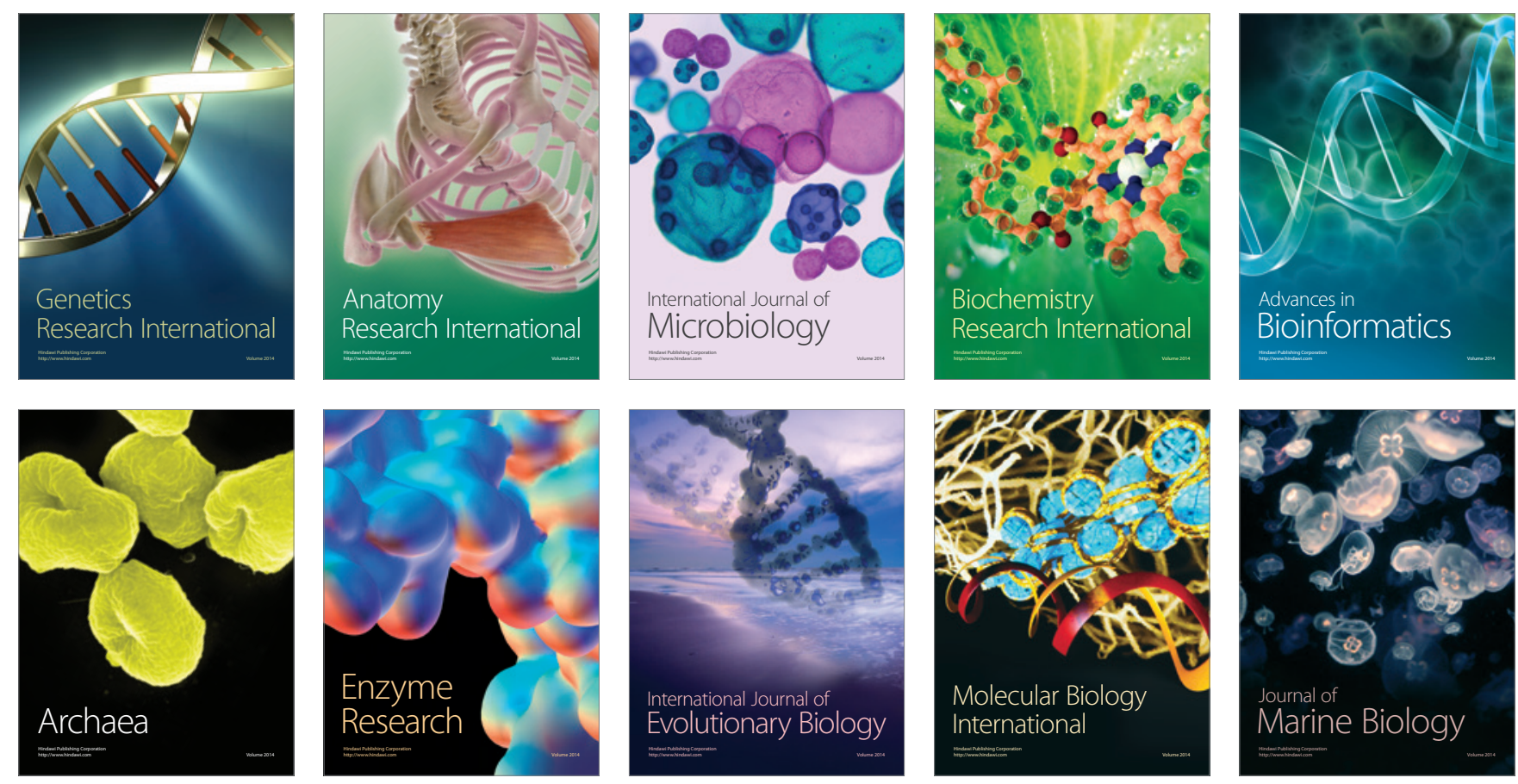